\title{
Iliopsoas Tendonitis following Total Hip Arthroplasty: Management of Nine Cases and Literature Review
}

\author{
K Narayanasetty* \\ Department of Locum Consultant in Orthopaedics, UK
}

*Corresponding author: K Narayanasetty, Locum Consultant in Orthopaedics; R Power, Consultant in Orthopaedics, Leicester, UK

Submission: 址 August 08, 2017; Published: 些 September 06, 2017

\section{Introduction}

After total hip arthroplasty some patients continue to have groin pain. Conditions that can cause groin pain include infection, aseptic loosening and soft tissue inflammation. Occasionally groin pain can be caused by the soft tissue inflammation in the form of tendonitis of the iliopsoas tendon. The reported incidence is as high as $4.3 \%$.

Most common site of iliopsoas impingement is at the anterior rim of the acetabulum are prominent acetabular component, extrusion of cement, reinforcement acetabular ring, retroverted or lateralised socket and psoas muscle can also be irritated by screws for acetabular fixation which have penetrated through the ilium. Symptoms can also caused by increased offset or significant lengthening of the leg (Figure 1).

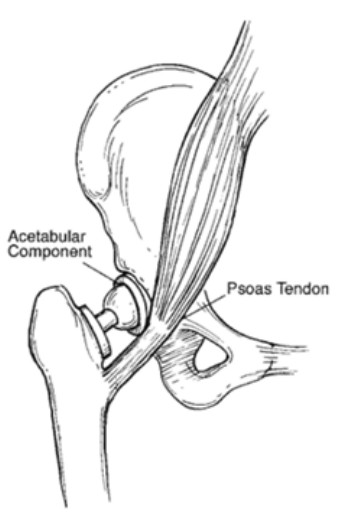

Figure 1

\section{Iliopsoas surgical anatomy}

Arises from the lumbar spine (psoas portion) and the inside of the iliac blade (iliacus portion). Exits the pelvis over the pelvic brim, passes over the anterior acetabular wall, and runs over the hip joint capsule curving around the femoral neck to insert into the lesser trochanter.

Primary role-hip flexion and external rotation. Tendon is intimately related to the anterior acetabular rim and to the native femoral head and neck.
When replacing the hip joint one needs to pay careful attention to the anterior rim of the acetabular component to ensure that it does not protrude beyond the bony acetabulum and potentially impinge on the iliopsoas tendon.

\section{Literature review}

First reported by Trousdale et al. [1] their 1995 case report described two patients with groin pain post-THR, both with retroverted acetabular components, were effectively treated by acetabular revision surgery. At the time of surgery the psoas tendon was noted to be frayed. Della Valle et al. [2] highlighted the phenomenon of psoas impingement and suggested surgical release of the tendon result in symptomatic cure.

In 2002 Jasani et al. [3] reported a series of nine patients with pain related to the psoas after THR. They coined the term of the 'car sign', a patient needs to manually lift their leg when getting out of a car. A surgical intervention to remove cementophytes and to trim anterior cup flanges irritating the psoas tendon was described. Two patients had uncemented cups with no obvious impingement and the authors considered an increased offset to be the cause and these patients where successfully treated with lengthening tenotomies of the psoas tendon.

Iliopsoas tendon dysfunction as a cause of pain after total hip arthroplasty relieved by surgical release. Taher et al. [4] reported that pain after Total Hip Arthroplasty (THA) may be due to a number of factors, including dysfunction of the iliopsoas tendon. They reported a case of persistent groin pain after THA. The pain was successfully treated using iliopsoas tenotomy rather than revision of any prosthetic component.

O'Sullivan et al. [5] described 16 hips with iliopsoas tendonitis. Fifteen of 16 hips were successfully treated with a psoas tendon release and one required a revision of the acetabular cup. [6] Total of 30 hips with oversized or malpositioned acetabular components was described in 29 patients. Eight patients then elected not to have any further surgery of the remaining 22 hips, six underwent a psoas tenotomy only while 16 had acetabular revision and psoas debridement. The surgical group did better overall then the non- 
surgical group. The acetabular revision showed no benefit over psoas release alone and had a greater number of complications. A psoas release alone was recommended for the majority of cases.

Odri [7] recently described oversized cups as a major risk factor for post-operative pain and proved that a cup size of $6 \mathrm{~mm}$ greater than the native femoral head was a statistically significant predictor of post-operative pain after total hip replacement.

O'Connor [8] describes the use of a specifically designed anatomical acetabular component in a revision case for a patient with psoas impingement. Iliopsoas impingement has also been described as a result of acetabular fixation screws penetrating the inner table of the ilium, from the collar of a femoral stem as well as from an oversized acetabular Compoment. Diagnosis of iliopsoas tendonitis

Diagnosis should be considered in patients complaining of pain in the groin during activities which require active hip flexion, such as walking up stairs, lifting the leg in and out of a car. (Car Sign)

Physical examination include difficulty in raising the leg to the examination couch, painful SLR or not possible and passive ROM and passive SLR is pain free.

Cross-table lateral view X-ray to confirm prominence of the acetabular component over the anterior aspect of the rim. All patients should undergo CT/US guided diagnostic Injection. Screen for infection with CRP and hip aspiration if necessary.

Case Series: Results

Table 1

\begin{tabular}{|c|c|c|c|c|}
\hline \multirow{2}{*}{ Cases } & THR Surgery & Psoas & Duration & Cause \\
\hline & & Release & After THR & \\
\hline Case $1 / 68 \mathrm{~F}$ & Dec-05 & Jun-07 & $19 \mathrm{M}$ & socket impingement - ABG CUP \\
\hline Case $2 / 67 \mathrm{M}$ & May-05 & Sep-07 & $28 \mathrm{M}$ & socket impingement - ABG CUP \\
\hline Case $3 / 66 \mathrm{~F}$ & Aug-05 & Nov-07 & $27 \mathrm{M}$ & socket impingement - ABG CUP \\
\hline Case $4 / 70 \mathrm{~F}$ & Jan-07 & Jun-08 & $18 \mathrm{M}$ & socket impingement - LEFT TRIDENT CUP \\
\hline Case $5 / 52 \mathrm{M}$ & 'Jan 2007 & Aug-08 & $18 \mathrm{M}$ & $\begin{array}{l}\text { Previous Acetabular Fracture - Plating \& socket } \\
\text { impingement }\end{array}$ \\
\hline Case 6/80F & Sep-08 & Jun-09 & $9 \mathrm{M}$ & Cemented socket/ ?leg lengthening - Muller Cup \\
\hline Case $7 / 47 \mathrm{~F}$ & Mar-06 & Nov-10 & $56 \mathrm{M}$ & osteophyte impingement, Dysplastic Hip - ABG CUP \\
\hline Case $8 / 50 \mathrm{M}$ & Oct-08 & Nov-10 & $25 \mathrm{M}$ & socket impingement - TRIDENT CUP \\
\hline Case $9 / 73 \mathrm{~F}$ & Jan 2010 & Jan-12 & $24 \mathrm{M}$ & socket impingement - LEFT TRIDENT CUP \\
\hline
\end{tabular}

At our institution we have surgically treated 9 patients with iliopsoas impingement post THR from Jun 2007 to Jan 2012. Table 1 shows demographic data and time since THR in individual cases. 7 out of 9 cases had evidence of socket impingement on radiographs.

\section{Iliopsoas tendonitis treatment}

Most optimal treatment is surgical release of liopsoas tendon as explained by Heaton [9]. The patients were placed supine on the operating table and the release was performed through a $5 \mathrm{~cm}$ horizontal incision approximately $2.5 \mathrm{~cm}$ below the inguinal skin crease and centered over the palpable border of the adductors.

Blunt dissection is carried out in a bloodless plain between pectineus and adductor brevis medial to the femoral artery. By flexing and externally rotating the hip one brings the lesser trochanter into the surgical field, and the psoas tendon can be divided under direct vision (Figure 2).

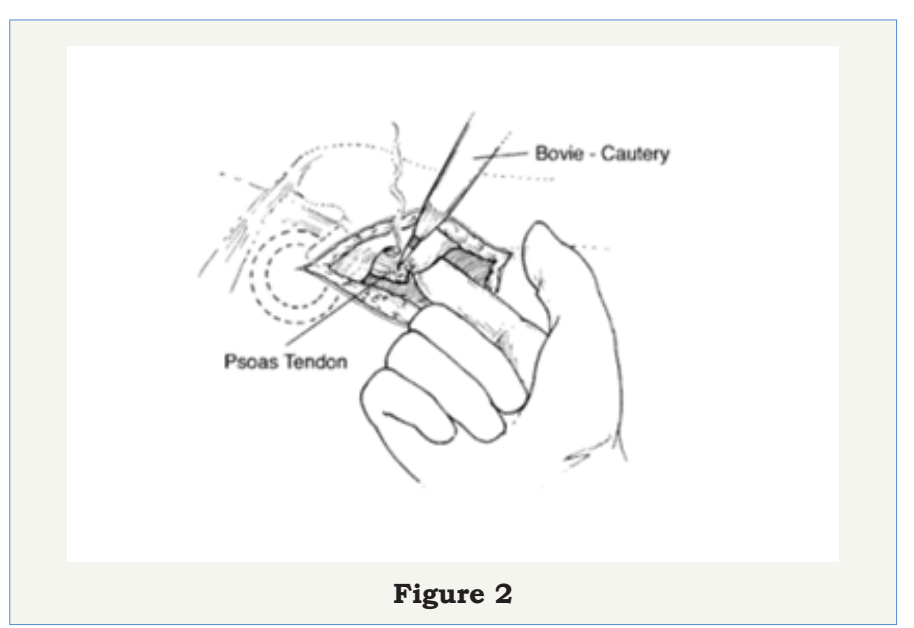

After investigations to exclude infection and diagnostic injection all 9 patients underwent open surgical release via a medial approach. Average period from THR surgery to tendon release was 24 months (Figure 3). 


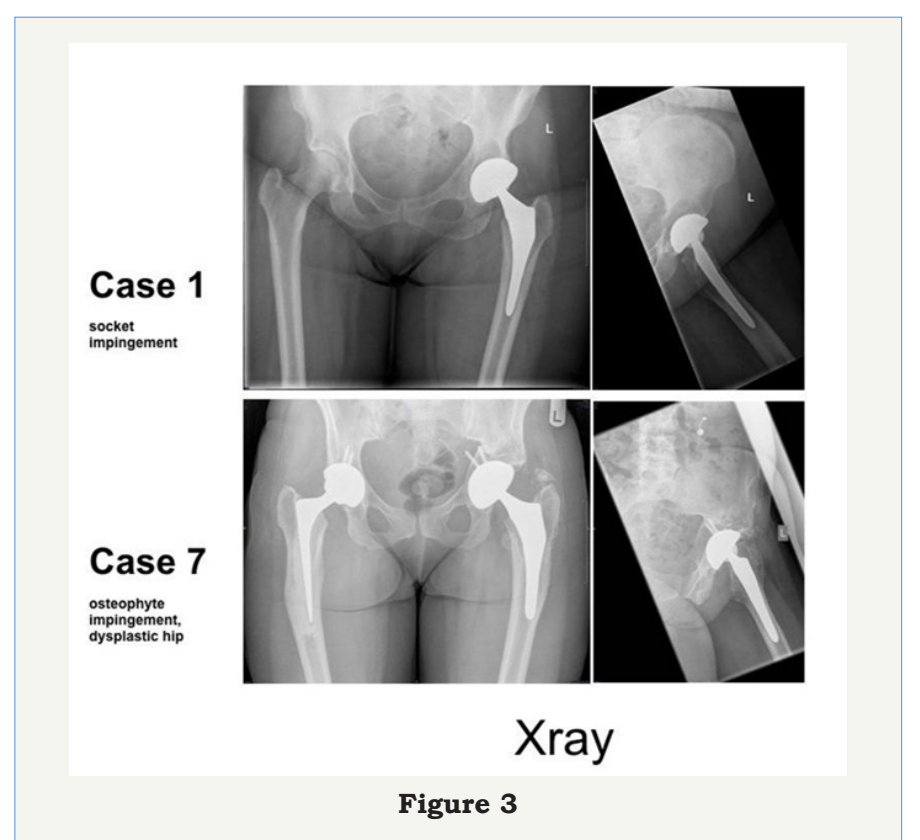

All patients underwent surgical release as described above. All cases, there were signs of irritation around the iliopsoas tendon. All patients were discharged within two days of the procedure and had symptomatic relief post surgery. By the 3-month follow-up their symptoms had completely resolved and they had all returned to their normal activities. None required revision of their acetabular components. There has been no recurrence of symptoms in any patients at latest follow up after 24 months.

\section{Discussion}

Our case series demonstrates that surgical management of iliopsoas impingement with tenotomy in presence of protruded acetabular component is successful in relieving pain in the groin in all the cases.

Use of conservative methods to treat Iliopsoas impingement including use of injections have been reported by many authors. Bricteux et al. [10] noticed no improvement in six patients who were treated conservatively with injections into the tendon sheath [11]. Noted recurrence at a mean of 3.7 months in eight of nine hips treated with CT-guided injections. Adler et al. [12] found an average of $50 \%$ improvement in ten patients at one year.

However, Ali Eddine et al. [13] at a minimum follow-up of three months, reported improvement in symptoms in five of nine patients after a first and second local injection. Three patients in their study did not have protruding cups and the reasons for the iliopsoas impingement were not mentioned of the remaining six hips, only two had improvement in symptoms after repeated injections. Previous reports have shown that the time to recurrence of symptoms is approximately 3.7 months [14].

One should consider diagnosis in patients with groin pain after hip arthroplasty. Evaluate with careful history, detailed examination and shoot-through lateral X-ray or CT is compulsory.
Protruding threaded metal-backed acetabular components screwed into bone have been suspected to be particularly at risk for anterior iliopsoas impingement [15]. Press-fit unthreaded cups and cemented polyethylene cups have been implicated in other reports, and are currently more likely to be seen in practice as causing iliopsoas impingement [16-18].

Injections into the psoas sheath can provide valuable information at the time of diagnosis and response to diagnostic injection is a definitive indication for Iliopsoas tendon release.

We had excellent results after surgery, Iliopsoas tenotomy was successful in the long term in all nine patients. It has also been used successfully by previous authors [19-21]. Patients who underwent tenotomy alone continued to improve clinically over a period of years, and none complained of weakness in flexion or when getting in or out of a car.

Tenotomy may be better suited for the management of iliopsoas impingement because of its low complication rate and the fact that it is not associated with a true long-term functional impairment [22].

However, in a young patient with good bone stock who has a prominent malpositioned cup, ace-tabular revision may be a better option. Revision and debridement of the psoas tendon has previously been shown to be successful in treating iliopsoas impingement associated with a prominent cup [23].

\section{References}

1. Trousdale RT, Cabanela ME, Berry DJ (1995) Anterior iliopsoas impingement after total hip arthroplasty. J Arthroplasty 10(4): 546-549.

2. Della Valle CJ, Rafii M, Jaffe WL (2001) Iliopsoas tendinitis after total hip arthroplasty. J Arthroplasty 16(7): 923-926.

3. Jasani V, Richards P, Wynn-Jones C (2002) Pain related to the psoas muscle after total hip replacement. J Bone Joint Surg Br 84(7): 991-993.

4. Taher RT, Power RA (2003) Iliopsoas tendon dysfunction as a cause of pain after total hip arthroplasty relieved by surgical release. J Arthroplasty 18(3): 387-388.

5. O'Sullivan M, Tia CC, Richards S, Skyrme AD, Walter WL, et al. (2007) Iliopsoas tendonitis a complication after total hip arthroplasty. J Arthroplasty 22(2): 166-170.

6. Dora C, Houweling M, Koch P, Sierra RJ (2007) Iliopsoas impingement after total hip replacement: The results of non-operative management, tenotomy or acetabular revision. J Bone Joint Surg Br 89(8): 1031-1035.

7. Odri GA, Padiolleau GB, Gouin FT (2014) Oversized cups as a major risk factor of postoperative pain after total hip arthroplasty. J Arthroplasty 29(4): 753-756.

8. Connor MI (2011) Use of an anatomical acetabular component for treatment of iliopsoas impingement. J Arthroplasty 26(8): 1570.e13-15.

9. Cyteval C, Sarrabere MP, Cottin A, Assi C, Morcos L, et al. (2003) Iliopsoas impingement on the acetabular component: radiologic and computed tomography findings of a rare hip prosthesis complication in eight cases. J Comput Assist Tomogr 27(2): 183-188.

10. Bricteux S, Beguin L, Fessy MH (2001) Iliopsoas impingement in 12 patients with a total hip arthroplasty. Rev Chir Orthop Reparatrice Appar Mot 87(8): 820-825. 
11. Bricteaux S, Seutin B, Beguin L, Farizon F, Fessy MH (2000) Arthroplastie totale de hanche douloureuse: rechercher les conflits avec le psoas: a propos de 10 cas. Rev Chir Orthop 86(Suppl II): 84-85.

12. Adler RS, Buly R, Ambrose R, Sculco T (2005) Diagnostic and therapeutic use of sonography-guided iliopsoas peritendinous injections. AJR Am J Roentgenol 185(4): 940-943.

13. Ali Eddine T, Remy F, Chantelot C, Giraud F, Miquad H, et al. (2001) Anterior iliopsoas impingement after total hip arthroplasty: diagnosis and conservative treatment in 9 cases. Rev Chir Orthop Reparatrice Appar Mot 87(8): 815-819.

14. Postel M. Painful prostheses: possible causes. Rev Chir Orthop Reparatrice Appar Mot 1975;61(Suppl II):57-61 (in French).

15. Lequesne M, Dang N, Montagne P, Lemoine A, Witvoet J (1991) Conflict between psoas and total hip prosthesis. Rev Rheum Mal Osteoarctic 58(9): 559-564.

16. Bader R, Mittelmeier W, Zeiler G, Tokar I, Steinhauser E, et al. (2005) Pitfalls in the use of acetabular reinforce- ment rings in total hip revision. Arch Orthop Trauma Surg 125(8): 558-563.

17. Meyer JD, Plötz W, Tillmann K, Russlies M (2002) Iliopsoas impingement after cement- less total hip arthroplasty: case reports. Orthopäde 31: 213-216.
18. Wank R, Miller TT, Shapiro JF (2004) Sonographically guided injection of anesthetic for iliopsoas tendinopathy after total hip arthroplasty. J Clin Ultrasound 32(7): 354-357.

19. Heaton K, Dorr LD (2002) Surgical release of iliopsoas tendon for groin pain after total hip arthroplasty. J Arthroplasty 17(6): 779-781.

20. Hauser R, Jacobs HA, Schreiber A (1996) The Balgrist hip socket for fixation without cement: analysis of 387 primary total hip replacements. Bull Hosp Jt Dis 54(3): 180-185.

21.Grubl A, Chiari C, Gruber M, Kaider A, Gottsauner-Wolf F (2002) Cementless total hip arthroplasty with a tapered, rectangular titanium stem and a threaded cup: a minimum ten-year follow-up. J Bone Joint Surg Am 84-A(3): 425-431.

22.Glassman AH, Engh CA, Bobyn JD (1987) A technique of extensile exposure for total hip arthroplasty. J Arthroplasty 2(1): 11-21.

23. Harris WH (1969) Traumatic arthritis of the hip after dislocation and acetabular fractures: treatment by mold arthroplasty: An end-result study using a new method of result evaluation. J Bone Joint Surg Am 51(4): 737-755. 